\title{
Evaluation of TSH, T4 and T3 in human serum: standardization on normal individuals
}

\author{
M. A. Samad', M. M. Haque ${ }^{1 . *}$, M. K. Shah' ${ }^{2}$ M. R. Islam², M. C. Mia ${ }^{1}$ \\ ${ }^{1}$ Department of Physics, Faculty of Science, University of Rajshahi, Rajshahi-6205, Bangladesh \\ ${ }^{2}$ Center for Nuclear Medicine \& Ultrasound, Rajshahi Medical College Hospital, Rajshahi, Bangladesh
}

\section{Email address:}

mhpdru@yahoo.com(M. M. Haque)

\section{To cite this article:}

M. A. Samad, M. M. Haque, M. K. Shah, M. R. Islam, M. C. Mia. Evaluation of TSH, T4 and T3 in Human Serum: Standardization on Normal Individuals. American Journal of Modern Physics. Vol. 2, No. 4, 2013, pp. 202-207. doi: 10.11648/j.ajmp.20130204.14

\begin{abstract}
A cross-sectional study of thyrotropin (TSH), thyroxine (T4) and triiodothyronine (T3) in human serum was performed aiming to define their normal values. In total, 201 assays were performed on 70 normal individuals, 26 men and 44 women, with ages ranging from 2 to 84 years. Serum TSH was measured with a highly sensitive immunoradiometric assay (IRMA) kit and T4 \& T3 were determined with commercially available radioimmunoassay (RIA) kits. The normal values of TSH, T4 and T3 observed in the present study were $0.5-5.0 \mathrm{mIU} / \mathrm{L}, 55-169 \mathrm{nmol} / \mathrm{L}$ and $1.2-3.4 \mathrm{nmol} / \mathrm{L}$, respectively, and their means $( \pm \mathrm{SD})$ were $2.06 \pm 1.08 \mathrm{mIU} / \mathrm{L}, 113.21 \pm 27.62 \mathrm{nmol} / \mathrm{L}$ and $1.96 \pm 0.54 \mathrm{nmol} / \mathrm{L}$, respectively. The results obtained were found to be in excellent agreement with the previously reported series. It is, therefore, expected that the present study will contribute some useful data in literature to set up normal values of serum TSH, T4 and T3.
\end{abstract}

Keywords: Thyroid Functions, Thyrotropin, Thyroxine, Triiodothyronine, Standardization

\section{Introduction}

The thyroid gland, in vertebrate anatomy, is one of the largest glands and normally located in the front of the neck[1-2]. This gland secretes several hormones, collectively called thyroid hormones (THs), which act throughout the body influencing metabolism, growth and development, and body temperature[3-5]. During infancy and childhood, adequate THs are crucial for brain development[6-12]. THs are also important in late brain development[11, 13-15]. Adult human hypothyroidism is associated with memory impairment and psychomotor slowing[16-19]. TH sensitivity of this phase of development is transient in nature.

An iodine deficiency thyroid disorder is one of the major public health problems in our country. In 1993, a nationwide iodine deficiency disorders (IDD) survey of Bangladesh showed that about $47.1 \%$ of our population had symptoms of goiter and nearly $69 \%$ of population has biochemical iodine deficiency[20]. However, the later IDD survey in 1999 reported that the biochemical iodine deficiency goiter rate was reduced to about $61 \%$ of the population[21]. Iodine deficiency still is the main cause of thyroid morbidity in Bangladesh. Therefore, evaluation of the functional status of thyroid gland is of a significant practical interest.

Thyroid diseases manifest mainly by qualitative or quantitative alteration in hormone secretion. The major thyroid hormone secreted by the thyroid gland is thyroxine, also called $\mathrm{T} 4$ because it contains four iodine atoms[21]. To exert its effects, T4 is converted to triiodothyronine (T3) by the removal of an iodine atom. The amount of T4 produced by the thyroid gland is controlled by another hormone, which is made in the pituitary gland, called thyroid stimulating hormone (TSH). TSH is, therefore, primarily responsible for the control of synthesis and secretion of the thyroid hormones. A high TSH level indicates that the thyroid gland is failing because of a problem that is directly affecting the thyroid (primary hypothyroidism). The opposite situation, in which the TSH level is low, usually indicates that the person has an overactive thyroid that is producing too much thyroid hormone (hyperthyroidism). Measurement of serum TSH, T4 and T3 has, therefore, become one of the most important tools in the diagnosis of thyroid disorders.

There is now a number of Centers of Nuclear Medicine \& Ultrasound (CNMU) and also diagnosis centers where serum TSH, T4 and T3 measurements are performed everyday in Bangladesh. All of these centers of course follow certain reference values for TSH, T4 and T3 as standards. It has been shown in the literature that normal values depend on the technique used and on the geographical location. Each laboratory should, therefore, establish its own normal values. In this paper, we have investigated the serum TSH, T4 and T3 values observed in some Bangladeshi normal individuals. 


\section{Materials and Methods}

The laboratory assessments used in the present study were carried out at the Center for Nuclear Medicine \& Ultrasound, Rajshahi, Bangladesh. Serum TSH was measured with a highly sensitive immunoradiometric assay (IRMA) kit (Beijing Atom Hightech Co. Ltd., Beijing) and T4 \& T3 were determined with commercially available radioimmunoassay (RIA) kits (Beijing Atom Hightech Co. Ltd., Beijing). The gamma ray spectra of the antibody-bound radio-labeled antigen were measured with a high-quality $\mathrm{NaI}$ borehole-type gamma counter (Multi Crystal LB 2111). Diagnostic results were calculated using logit-log plotting. After introduction in 1960 by Berson and Yalow, both RIA \& IRMA have been described in details over the years in several publications[22-25]. Here, we give only some salient features relevant to the present investigation.

\subsection{Specifications of Sample}

In total, 210 assays were performed in 70 individuals with no clinical evidence of thyroid disorder. The samples were from different districts of Rajshahi division, one of the iodine-deficient zones in Bangladesh. The thyroids of all the individuals were in clinically normal condition. Among the individuals 26 were men and 44 women, with ages ranging from 2 to 84 years. More than $50 \%$ of the individuals were within the age range of $20-40$ years, $75 \%$ were in 10-50 years and more than $90 \%$ were within $10-60$ years. The mean age of the studied subjects was $33.44 \pm 16.45$ years.

\subsection{Radioimmunoassay (RIA) Procedure}

The radioimmunoassay (RIA) involves the separation of a protein (from a mixture) using the specificity of antibody-antigen binding and quantitation using radioactivity. It depends on the competition between radiolabeled antigens and unlabeled antigen for a fixed and limited number of antibody binding sites. RIA requires the antigen to be labeled with a radioisotope, such as ${ }^{125} \mathrm{I},{ }^{14} \mathrm{C}$ or ${ }^{3} \mathrm{H}$. In the present study, the optimum binding conditions between the antigen and antibody were first determined and then the appropriate buffer, $\mathrm{pH}$, binding incubation time, and temperature were chosen. Secondly, a fixed concentration of radiolabeled antigen with a constant amount of antibody was incubated so that the total antigen binding sites on the antibody were limiting. In a typical RIA, only $30-50 \%$ of the total radiolabeled antigen can be bound to the antibody in the absence of unlabeled antigen. Thirdly, an increasing amount of unlabeled antigen, as a standard, was added to this system. This results in competition between radiolabeled antigen and unlabeled antigen for the limited number of binding sites on the antibody. The amount of radiolabeled antigen bound to antibody decreases as the concentration of unlabeled antigen increases. In next step, antibody-bound radiolabeled antigen was separated from unbound radiolabeled antigen using a technique of double antibody extraction. In this technique, which is most commonly used, a precipitating reagent is added, which consists of a secondary antibody that recognizes the primary antibody mixed with polyethylene glycol. The precipitating reagent is then mixed with the RIA reaction and centrifuged to isolate the insoluble pellet that contains only the bound radiolabeled antigen.

After separating from free radio-labeled antigen, the antibody-bound radio-labeled antigen was immediately taken into the nearby gamma-ray spectrometry laboratory for counting radioactivity. The counts for each of the standards were expressed as a percentage of the mean counts of the zero standards using the following formalism:

$$
\frac{B}{B_{0}} \%=\frac{B \text { of standard }}{B_{0}} \times 100 \%
$$

where $\mathrm{B}$ is the count of each standard, and $\mathrm{B}_{0}$ is the mean count rate for the zero standards. A calibration curve was generated by plotting $\mathrm{B} / \mathrm{B}_{0}$ for each standard against the hormone (T3 or T4) concentration on logit-log graph paper. Required hormone (T3 or T4) concentration was then read off directly from the curve for each of the unknown samples. Note that the radioactivity counts in the bound fraction are inversely related to the unlabeled antigen concentration[26].

\subsection{Immunoradiometric Assay (IRMA) Procedure}

Immunoradiometric assay (IRMA) is based on the reversible and non-covalent binding of an antigen by a specific antibody labeled with a radioactive nuclide as a tracer. It is an alternative method to radioimmunoassay for the measurement of very small amounts of nonradioactive material. An excess amount of a specific antibody labeled with a radioactive isotope is added to the sample containing the substance to be assayed. After equilibration, unreacted antibody is removed and the amount of radioactive material remaining is measured.

In the present study, the CIAE TSH IRMA kit utilizes a two-site sandwich immunoradiometric assay for the measurement of TSH in human serum. This involves the reaction of TSH present in serum with monoclonal and polyclonal antibody. The monoclonal antibody was labeled with $125 \mathrm{I}$ as tracer (125I-McAb) and the polyclonal antibody was coupled to magnetic iron oxide particles $(\mathrm{PcAb}<\mathrm{M}\rangle)$. The formed 125I-McAb-TSH-PcAb $<\mathrm{M}>$ complex (sandwich) was separated from unbound tracer by placing the assay tubes in the magnetic separator and decanting supernatant. The gamma-ray spectra were then measured by taking it into the nearby gamma-spectrometry laboratory. It should be noted that the measured radioactivity counts are directly related to the antigen concentration[26].

A calibration curve was generated by plotting the count rate for each standard tube against the TSH concentration on Log-Log graph paper. The best curve was drawn through the mean of duplicate points, rejecting grossly aberrant counts. Finally, the TSH concentration of each unknown was read off by fitting their mean count rate in this standard curve. 


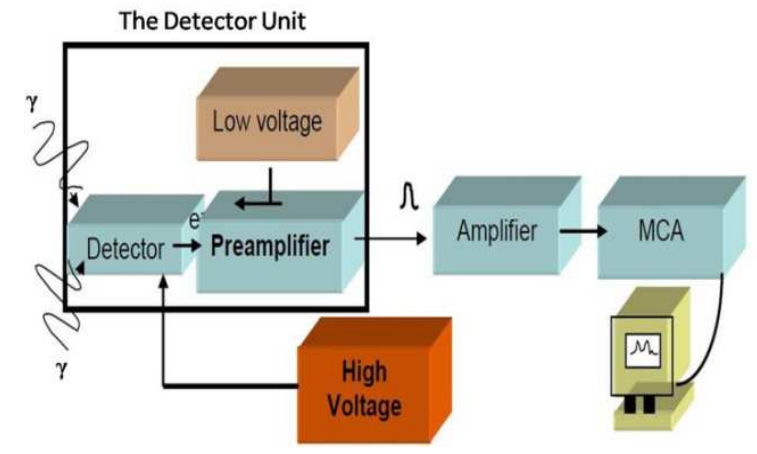

Figure 1. A schematic drawing of the measuring geometry of gamma-ray spectroscopy.

\subsection{Gamma-ray Spectroscopy}

Immediately after separating the antibody-bound radio-labeled antigen (in the case of $\mathrm{T} 4 \& \mathrm{~T} 3$ ) and ${ }^{125} \mathrm{I}-\mathrm{McAb}-\mathrm{TSH}-\mathrm{PcAb}\langle\mathrm{M}\rangle$ complex (in the case of TSH) from their respective free portion, the samples were taken to the nearby gamma spectrometry laboratory for counting. The gamma-ray spectra were measured with a high-quality NaI borehole-type gamma counter (Multi Crystal LB 2111) coupled to a pre-amplifier, amplifier, analogue-to-digital converter (ADC) and multi channel analyzer (MCA). Fig. 1 shows a schematic drawing of the measuring geometry.

The Multi Crystal LB 2111 gamma counter is available as a 12-detector unit, made of high-quality $\mathrm{NaI}$ borehole "well type" crystals providing best measurement geometry for $\gamma$-emitters located in a sample tube. The crystals cover an energy range up to $500 \mathrm{KeV}$ suitable for the common isotopes, e.g. ${ }^{125} \mathrm{I},{ }^{57} \mathrm{Co},{ }^{59} \mathrm{Fe},{ }^{51} \mathrm{Cr}$ and ${ }^{99} \mathrm{Tc}$. A thick lead shield of $6 \mathrm{~mm}$, i.e. in total $12 \mathrm{~mm}$ of lead surrounding each of the detectors efficiently prevents crosstalk between the samples in the individual detectors. For specific loading patterns any of the detectors can be disabled individually. Exchangeable plastic liners prevent detector contamination. The standardization procedure corrects for slight variations in detector efficiencies. Either a single tube containing the isotope, e.g. ${ }^{125} \mathrm{I}$, is sequentially counted in each of the detectors or 12 tubes, each with the same amount of activity, are counted simultaneously in all 12 detectors. Along with the standardization the high voltage supply is optimized for each detector.

\section{Results and Discussion}

The experimental results observed in the present study are summarized in Table 1. The uncertainties quoted in the values represent the statistical and systematic errors. The great majority of the samples involved in this study were from females and most of the individuals (both female and male) were within the range of 20-50 years of age. The Mean \pm SD of age was $33.44 \pm 16.45$ years. Fig. 2 shows histograms of frequencies of serum TSH, T4 and T3. The frequency histograms revealed a non-Gaussian data distribution. Therefore, the mean and standard deviation $( \pm \mathrm{SD})$ values did not represent these normal distribution curves.
Table 1. Results obtained in the present study for serum TSH, T4 and T3.

\begin{tabular}{ccc}
\hline Hormone & Observed range & Mean value \\
\hline $\mathrm{TSH}(\mathrm{mIU} / \mathrm{L})$ & $0.5-5.0$ & $2.06 \pm 1.08$ \\
$\mathrm{~T} 4(\mathrm{nmol} / \mathrm{L})$ & $55-169$ & $113.21 \pm 27.62$ \\
$\mathrm{~T} 3(\mathrm{nmol} / \mathrm{L})$ & $1.2-3.4$ & $1.96 \pm 0.54$ \\
$\mathrm{~T}_{3} / \mathrm{T}_{4}(\mathrm{nmol} / \mu \mathrm{mol})$ & - & $18.27 \pm 5.69$ \\
\hline
\end{tabular}

Table 2. Distribution of serum TSH, T4 and T3 values previously cited in the literature, and reference values followed by different hospitals in Bangladesh.[CNMU = Center for Nuclear Medicine \& Ultrasound; $\mathrm{MCH}$ = Medical College Hospital].

\begin{tabular}{cccc}
\hline Reference & $\begin{array}{c}\text { TSH } \\
(\mathbf{m I U} / \mathbf{L})\end{array}$ & $\begin{array}{c}\text { T4 } \\
\text { (nmol/L) }\end{array}$ & $\begin{array}{c}\text { T3 } \\
(\mathbf{n m o l} / \mathbf{L})\end{array}$ \\
\hline M.K. Shah[30] & $0.4-3.1$ & $76-176$ & $1.2-3.2$ \\
Sills et al.[29] & $0.6-4.8$ & $58-155$ & $1.2-3.1$ \\
S.R. Joshi[34] & $0.5-4.7$ & $58-140$ & $0.9-2.8$ \\
CNMU, Dhaka & $0.6-4.8$ & $54-173$ & $1.2-3.5$ \\
CNMU, Rajshahi & $0.3-5.0$ & $54-173$ & $1.2-3.5$ \\
CNMU, & $0.3-5.0$ & $52-173$ & $0.8-3.2$ \\
Mymensingh & $0.3-5.0$ & $52-173$ & $0.8-3.2$ \\
CNMU, Sylhet & $0.3-5.0$ & $54-173$ & $1.2-3.5$ \\
MCH, Dhaka & $0.4-4.8$ & $54-174$ & $1.3-3.4$ \\
MCH, Dinajpur & $0.3-5.0$ & $54-173$ & $1.2-3.5$ \\
MCH, Khulna & $0.3-5.0$ & $54-173$ & $1.2-3.5$ \\
MCH, Faridpur & $0.5-5.0$ & $55-169$ & $1.2-3.4$ \\
\hline Present study & & & \\
\hline
\end{tabular}

Table 2 illustrates the comparison of measured TSH, T4 and T3 values with those previously cited in the literature, and reference values used by different hospitals in the country. The discrepancies among the reported series could be due to the different techniques used and the population studied. In the standard textbooks[3-4], however, there are no age and sex dependent TSH, T4 and T3 values in adults, but recently a number of researchers[27-29] suggested the age and sex adjustment range of TSH, T4 and T3. It should also be noted that M.K. Shah[30] studied euthyroids whereas others considered only normal healthy individuals as their study groups. All of these factors could be the causes for the non-normality of experimental data distributions. On the other hand, the reference values used by most of the hospitals might be taken from the guidelines issued by the National Academy of Clinical Biochemistry, USA[31].

The box-plot analysis of serum TSH histogram showed that more than $50 \%$ of the normal individuals had TSH values that ranged from $1.0 \mathrm{mIU} / \mathrm{L}$ to $2.5 \mathrm{mIU} / \mathrm{L}$, about $70 \%$ ranged from $0.5 \mathrm{mIU} / \mathrm{L}$ to $2.5 \mathrm{mIU} / \mathrm{L}$, and more than $90 \%$ ranged from $0.5 \mathrm{mIU} / \mathrm{L}$ to $3.5 \mathrm{mIU} / \mathrm{L}$. The frequency histogram of $\mathrm{T} 4$ showed that $50 \%$ of the normal individuals had T4 values that ranged from $93 \mathrm{nmol} / \mathrm{L}$ to $131 \mathrm{nmol} / \mathrm{L}$, $75 \%$ ranged from $93 \mathrm{nmol} / \mathrm{L}$ to $156 \mathrm{nmol} / \mathrm{L}$, and about $97 \%$ ranged from $55 \mathrm{nmol} / \mathrm{L}$ to $156 \mathrm{nmol} / \mathrm{L}$. T3 histograms showed that $50 \%$ of the normal individuals had $\mathrm{T} 3$ values 
that ranged from $1.4 \mathrm{nmol} / \mathrm{L}$ to $2.2 \mathrm{nmol} / \mathrm{L}, 80 \%$ ranged from $1.2 \mathrm{nmol} / \mathrm{L}$ to $2.4 \mathrm{nmol} / \mathrm{L}$, and more than $90 \%$ ranged from $1.2 \mathrm{nmol} / \mathrm{L}$ to $2.8 \mathrm{nmol} / \mathrm{L}$.

$\mathrm{TSH}$ assay is very sensitive in detecting even subtle thyroid dysfunction[32, 33]. Measurement of serum TSH concentration is, therefore, the most useful single laboratory test in the initial evaluation of thyroid disorders, especially thyroid nodules. The normal range of TSH found in the present study was $0.5-5.0 \mathrm{mIU} / \mathrm{L}$, which is in accordance with the ranges suggested in standard textbooks[3-5] as well as used by most of the hospitals in USA[31]. The upper limit of the range is in excellent agreement with the reported series, except with that reported by M.K. Shah[30]. The lower limit of normality in this study is also in good agreement with the values previously cited in the literature[29, 30, 34], but slightly lower than reference values used by most of the hospitals. The mean value of TSH observed in this study was $2.06 \pm$ $1.08 \mathrm{mIU} / \mathrm{L}$, which is also different from that previously reported in[29] as $2.32 \pm 0.21 \mathrm{mIU} / \mathrm{L}$ and in[30] as $1.34 \pm$ $0.54 \mathrm{mIU} / \mathrm{L}$. These differences could be due to the different techniques used and the population studied.

In the case when TSH is not within the normal range, the estimation of serum T4 and T3 can provide with significant information regarding the functional status of the thyroid. Thyroid hormone, in thyroid gland, is stored in the form of $\mathrm{T} 4$, which is converted into T3 for normal activity of our body. An intrinsic abnormality in the process of thyroid hormone synthesis decreases the production of thyroid hormones, especially T4, and thereby TSH is increased. As a consequence of increased TSH secretion, iodine turnover by the thyroid is accelerated and the ratio of $\mathrm{T} 3$ to $\mathrm{T} 4$ is increased, but serum $\mathrm{T} 3$ remains entirely normal.

In the present study the observed range of serum $\mathrm{T} 4$ was $55-169 \mathrm{nmol} / \mathrm{L}$, which is in excellent agreement with that reported in[31]. This range was also in fairly good agreement with the reported series and also with the reference except the lower limit reported in[30] and the upper limit reported in[31].

The range of serum T3 observed in this study was 1.2 $3.4 \mathrm{nmol} / \mathrm{L}$. The lower limit of this normality is in excellent agreement with most of the reported series as well as with the reference values except with that used by CNMU at Mymensingh and CNMU at Sylhet. The upper limit of normality is also in excellent agreement with the values used by different CNMUs and hospitals except again with that used by CNMU at Mymensingh and CNMU at Sylhet. But, the upper values of the reported series are slightly lower than our observed value. Both the upper and lower limits reported in[34] are remarkably different from the present study. The elevated level of T3 in the present study may be due to the effect of sex hormones such as estrogens and progesterone, since the majority of the individuals within the sample in the this study were women. This pattern of effect is also in agreement with the findings reported in[27]. Again, the mean values of T3 and T4 obtained in this study were $1.96 \pm 0.54 \mathrm{nmol} / \mathrm{L}$ and 113.21 $\pm 27.62 \mathrm{nmol} / \mathrm{L}$, respectively, which are slightly higher than the reported values[29, 30, 34]. On the other hand, the obtained ratio of $\mathrm{T} 3$ to $\mathrm{T} 4$ was $18.27 \pm 5.69 \mathrm{nmol} / \mu \mathrm{mol}$, which is in good agreement with that reported in[35], but slightly higher than that reported in[30]. It may be argued that the subjects in those studies were not screened for any kind of illness that may affect the thyroid function tests. But in the present work we selected only the normal and healthy individuals and, therefore, the observed ranges for the reported cases were significantly different from our case.
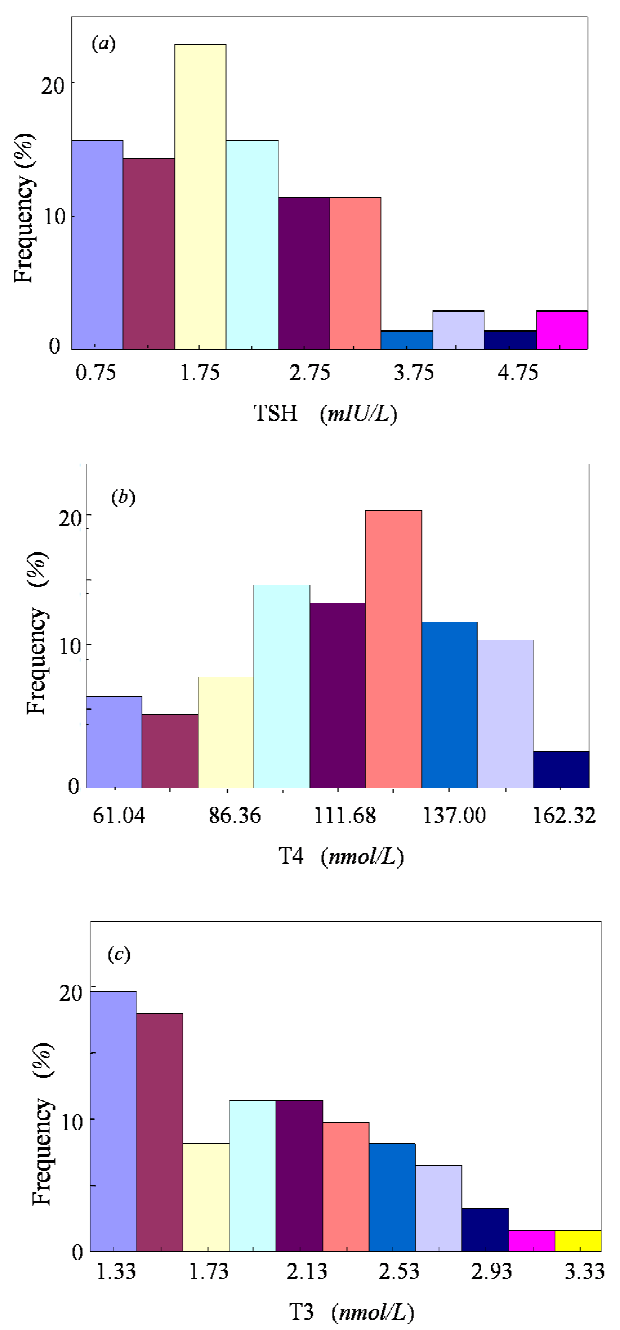

Figure 1. Frequency histograms of serum (a) TSH, (b) T4, and (c) T3; measurement of 70 normal individuals.

\section{Conclusions}

In this study, serum TSH, T4 and T3 were measured in 70 normal individuals using IRMA and RIA methods. The aim of this study was to define the normal ranges for TSH, T4 and T3. The results obtained were compared with the previously cited values and were found to be in excellent agreement (except for a few cases). It is, therefore, expected that the present study will contribute some useful data in literature. Particularly, this study will be useful to set up the own reference value of TSH, T4 and T3 for the center of Nuclear Medicine and Ultrasound (CNMU), Rajshahi, Bangladesh. 


\section{Acknowledgements}

This study was supported by the research grant provided by the Faculty of Science, University of Rajshahi, Bangladesh. We are very thankful to all medical officers, scientific officers, technicians and all other stuffs of the Center for Nuclear Medicine \& Ultrasound (CNMU), Rajshahi, for their kind help and suggestions during this research.

\section{References}

[1] S. Reza, Basic Human Anatomy and Physiology, Mediaplex publisher \& Distributor: Dhaka, 2011, pp. 193.

[2] W.F. Ganong, The Thyroid Gland in Review of Medical Phy sinology, The MeGraw Hill Companies: Newyork, 2011, pp. 307.

[3] I.E. Griffin and S. R. Objeda, The Textbook of Endocrine Physiology, New York: Oxford University Press, 1988, pp. $222-232$

[4] T.E. Andreali, C.C. Bannet, F.C. Plum, Plum, Textbook of Medicine, $4^{\text {th }}$ Edition, Philadelphia: Saunder \& Co, 1997, p. 952-953.

[5] R.K. Murry, P.K. Gerner, P.A. Mays, V.W. Harper's Rodwel, Textbook of Biochemistry, $25^{\text {th }}$ Edition, Appleton \& Lange: Stanford, 2000, pp. 8.

[6] de Escobar G. Morreale. "The role of thyroid hormone in fetal neurodevelopment" J. Pediatr. Endocrinol Metab., 2001, vol. 14, No. (Suppl 6), pp. 1453-1462.

[7] de Escobar G. Morreale, M. J. Obregon and del Rey F. Escobar. "Is neuropsychological development related to maternal hypothyroidism or to maternal hypothyroxinemia?" J. Clin. Endocrinol Metab., 2000, vol. 85, pp. 3975-3987.

[8] G. Mirabella, D. Feig, E. Astzalos, K. Perlman and J.F. Rovet. "The effect of abnormal intrauterine thyroid hormone economies on infant cognitive abilities" J. Pediatr. Endocrinol Metab., 2000, vol. 13, pp. 191-194.

[9] A.L. Dowling, E.A. Iannacone and R.T. Zoeller. Maternal hypothyroidism selectively affects the expression of neuroen-docrine-specific protein a messenger ribonucleic acid in the proliferative zone of the fetal rat brain cortex" Endocrinology, 2001, vol. 142, pp. 390-399.

[10] P.A. Piosik, M. van Groenigen, J. van Doorn, F. Baas and J. J. de Vijlder. "Effects of maternal thyroid status on thyroid hormones and growth in congenitally hypothyroid goat fetuses during the second half of gestation endocrinology" 1997, vol. 138, pp. 5-11.

[11] X. Y. Cao, X. M. Jiang, Z. H. Dou, M. A. Rakeman, M. L. Zhang, K. O'Donnell, T. Ma,K. Amette, N. DeLong and G. R. DeLong. "Timing of vulnerability of the brain to iodine deficiency in endemic cretinism" N. Engl. J. Med., 1994, vol. 331, pp. 1739-1744.

[12] T. Vulsma, M. H. Gons and J. J. de Vijlder. "Maternal-fetal transfer of thyroxine in congenital hypothyroidism due to a total organification defect or thyroid agenesis" N. Engl. J. Med., 1989, vol. 321, pp. 13-16.

[13] J. Bernal. "Action of thyroid hormone in brain" J. Endocrinol Invest., 2002. vol. 25, pp. 268-288.
[14] C. C. Thompson and G. B. Potter. "Thyroid hormone action in neural development" Cereb. Cortex., 2000, vol. 10, pp. 939-945.

[15] N. Koibuchi and W. W. Chin. "Thyroid hormone action and brain development trends" Endocrinol Metab, 2000, vol. 11, pp. 123-128.

[16] P. C. Whybrow and M. Bauer, "Behavioral and psychiatric aspects of thyrotoxicosis," in The thyroid: fundamental and clinical text, L. E. Braverman and R. D. Utiger, Eds. Lippincott Williams and Wilkins: Phila-delphia, 2000), pp. 673.

[17] S. C. Boyages, "The neuromuscular system and brain in thyrotoxicosis," in The thyroid: a fundamental and clinical text, L. E. Braverman, R. D. Utiger, Eds. Lippincott Williams and Wilkins, Philadelphia, 2000, pp. 631.

[18] I. M. Baldini, A. Vita, M. C. Mauri, V. Amodei, M. Carrisi, S Bravin and L. Cantalamessa. "Psychopathological and cognitive features in subclinical hypothyroidism" Prog. Neuropsy-chopharmacol Biol. Psychiatry., 1997. vol. 21, pp. 925-935.

[19] D. Osterweil, K. Syndulko, S.N S. N. Cohen., P.D. P. D. Pettler-Jennings, J. M. Hershman, J. L. Cummings, W. W. Tourtellotte and D. H. Solomon. "Cognitive function in non-demented older adults with hypothyroidism" J. Am. Geriatr. Soc., 1992, vol. 40, pp. 325-335.

[20] H. K. M. Yusuf, S. Quazi, M. R. Khan, M. Mahmuduzzaman, B. Nahar, M. M. Rahman, M. N. Islam, M. A. Khan, M. Shahidullah, I. Haque, M. Baquer and C. S. Panday. "Iodine deficiency disorders in Bangladesh" Indian J. Pediatr., 1996, vol. 63, pp. 105-110.

[21] Q. Salamatullah, M. Rapid, H. K. M. Yusuf, N. Islam, M. N. Alam, M. A. Hasnat, M. Faruque et al. "Iodine disorder survey in Bangladesh" Dhaka University, 1999.

[22] S. Glick. "Rosalyn sussman yalow (1921-2011)" Nature, 2011, vol. 474 (7353), pp. 580.

[23] K. Y. Waite, C. F. Maberly and C. J. Eastman. "Immunoradiometric assay with use of magnetizable particles" Clin. Chem., 1986, vol. 32, No 10, pp. 1966-1968.

[24] W. D. Odell, Z. Criffin and R. Zahradnik. "Two-monoclonal-antibody sandwish-type assay for thyrotropin with use of an avidin-biotin separation technique" Clin. Chem., 1986, vol. 32, No 10, pp. 1873-1878.

[25] F. Thomas, Teddari and M. Edward Hoffmann. "Immunoradiometric assay for examination and quantitation of brucella abortus-specific antibodies reactive with the antigen(s) used in the indirect hemolysis test" J. Clin. Microbiol., 1981, vol.14, No 4, pp. 415-426.

[26] A. V. Heal, "Radioassay," in Principles \& practice of nuclear medicine, P. J. Early and D. B. Sodeel, Eds., Inc C.V. Mosby Company: St Louis, 1985, pp. 856.

[27] Zahoor Ahmed, Mudassir Ahmad Khan, Amin ul Haq, Salma Attaullag and Zamil ur Rehman. "Effect of race, gender and age on thyroid and thyroid stimulating hormone levels in northwest frontier province, Pakistan" J Aub Med Coll abbottabad, 2009, vol. 21, No 9, pp. 21-24.

[28] Pallavi Chaurasia, Bhautik Modi, Sarita Mangukiya, Pranay Jadav and Rita Shah. "Variation of thyroid hormones level among people of different age, gender and seasons, Piparia, Gujarat" National Journal of Medical Research, 2011, vol. 1, No 2, pp. 57-59. 
[29] I. N. Sills, M. N. B. Horlick and R. Rapaport. "Inappropriate suppression of thyrotropin during medical treatment of graves' disease in childhood" J. Pediatr., 1992, vol. 163, pp. 262-263.

[30] M. K. Shah, MPhil Thesis, University of Dhaka (Bangladesh), 2009.

[31] Mary J. Shomon. "The TSH reference range wars: what's "normal?" who is wrong, who is right, and what does it all mean for you and your health?" Sticking Out Our Necks, 2005, December 4, pp. 1-5.
[32] A. Meller, T. J. Loy and A. J. Herle. "Diagnosis and management of solitary thyroid nodules" Br J Surg., 2002, vol. 78 , pp. 90-93.

[33] A. R. Spencer, B. M. Jaffe and J. C. Moron. "Hyperthyroidism and concurrent thyroid malignancies" Sur., 1990, vol. 106, pp. 6-10.

[34] S. R. Joshi, "Laboratory evaluation of thyroid functions" JAPI, 2011, vol. 49, pp. 14-20.

[35] M. C. Miah, MSc Thesis, University of Rajshahi (Bangladesh), 2012 